\title{
A META(PERSONA)LINGUAGEM EM FERNANDO PESSOA
}

\author{
Rogério Caetano de Almeida ${ }^{1}$
}

RESUMO: Este texto visa discutir como a identidade do eu-lírico se coaduna com o próprio trabalho metalingüístico na obra de Fernando Pessoa e seus heterônimos. A discussão é fulcral para compreender a obra de um artista que forneceu múltiplas facetas de sua(s) poética(s) criada com o que chamamos neste trabalho de meta(persona)linguagem.

PALAVRAS-CHAVE: Fernando Pessoa; heterônimos; metalinguagem.

\begin{abstract}
This text aims to discuss how the identity of the "I" in the poem joins the actual metalinguistic work in Fernando Pessoa's literature and heteronyms. This discussion is mandatory to understand the work of an artist who provided many facets of his poetic created with what we call here as meta(persona)language.
\end{abstract}

KEYWORDS: Fernando Pessoa; heteronyms; metalanguage.

\footnotetext{
${ }^{1}$ Mestre em Estudos Comparados e doutorando na área de Literatura Portuguesa - USP sob orientação de Prof. Dr. Horácio Costa.
} 


\title{
Introdução
}

\begin{abstract}
"O artista subjetivo parte do princípio que o fim da sua arte é exprimir as suas próprias emoções. Critério é esse que o artista objectivo não aceita, e como razão absoluta o não aceita, porque a arte objectiva é que é a arte, por isso que é uma cousa realizada, que passa para fora do artista, e não fica nele, como a emoção que a produz." Fernando Pessoa
\end{abstract}

Como diria Fernando Segolin em seu trabalho, "mais uma vez Pessoa" (SEGOLIN, 1992, p. 12). O gênio do autor português ainda assusta e fascina. O encanto que Fernando Pessoa exerce nos leitores de sua obra não é casual. A grande necessidade do homem é buscar uma solução para seus grandes questionamentos. "Quem sou?; Para onde vou?; De onde vim?". E todos os trabalhos que são feitos sobre a obra de Pessoa são "uma indagação sobre a identidade" (SEGOLIN, 1992, p.15).

Quando alguém se pergunta sobre a identidade de si mesmo e lê a obra de Pessoa com sua total despersonalização, chega-se à clássica conclusão de Heráclito: "o ser não é mais que o não-ser". A vontade que o "supra-camões" tem de descobrir sua identidade fica equilibrada com sua falta de vontade de descobrir (evidente, por exemplo, no poema XXVIII de $O$ Guardador de Rebanhos, do heterônimo Alberto Caeiro).

O problema da identidade do eu-poemático é fulcral em toda a obra pessoana. Porém, este trabalho abordará a identidade de outra maneira. A identidade da linguagem de Pessoa. Como sua obra lida com a identidade da linguagem dentro da própria linguagem, ou seja, como a obra de Pessoa se identifica com a linguagem? Como ocorre a metalinguagem no texto pessoano?

A questão, por demais complexa, merece um estudo da obra completa de Pessoa, mas como tudo é muito abstruso na obra de Pessoa, esta, analisada como um todo, só poderá nos fornecer muitas respostas, não uma única. Nem mesmo um heterônimo em particular dará uma resposta só, como o próprio Caeiro nos mostra: "Não sei o que é a Natureza: (...) E essa é a minha definição.” (PESSOA, 1999, p. 27)

Tendo o fazer textual e a reflexão sobre este como objeto de estudo, há uma tentativa de conseguir relacioná-los (ou não) através da produção de poemas metalingüísticos. Todavia, nunca devemos nos esquecer do que diz Pessoa sobre a crítica: "A crítica é, em suma, todo o artifício que é feito com inteligência, e sem fim 
social nenhum. Desde que sirva um ideal em vez de uma impressão [?], a crítica é falsa como crítica, não é crítica, em suma, mas só opinião.” (PESSOA, 1988, p. 47)

Partindo dos pressupostos de que a metalinguagem é devera complexa na obra de Fernando Pessoa e de que a crítica é uma especulação, este trabalho se deterá brevemente na descrição da metalinguagem em todos os heterônimos e na obra do Pessoa ortônimo, pois eles ajudarão a (não) desenvolvê-la, assim "não se chega a determinar com clareza o papel cambiante que a palavra e o texto de Pessoa procuram assumir diante do real, no afã de exorcizar a incapacidade representativa da linguagem" (SEGOLIN, 1992, p. 27).

É importante frisar que tudo será analisado dentro do (uni)verso textual do autor, pois todos os heterônimos são "texto-personagem" que se comprometem apenas, na condição de seres escritos, a fazerem o texto. Assim, enquanto seres escritos, a metalinguagem chega de que maneira ao Ser indivíduo ou ser-heterônimo?

\section{A meta(persona)linguagem em Fernando Pessoa}

"Tenho construido em passeio frases perfeitas de que depois me não lembro em casa. A poesia inefável dessas frases não sei se será parte do que foram, se parte de não terem nunca sido." Bernardo Soares

O termo meta se origina no latim meta e significa alvo, mira. A palavra linguagem surge no provençal lenguatge e, grosso modo, é o conjunto de sinais falados, escritos ou gesticulados de que se serve o homem para exprimir idéias e sentimentos. Nas palavras de Haroldo de Campos, quando aplicamos o termo metalinguagem nas artes, "Crítica é metalinguagem. Metalinguagem ou linguagem sobre a linguagem. $\mathrm{O}$ objeto - a linguagem-objeto - dessa metalinguagem é a obra de arte, sistema de signos dotado de coerência estrutural e de originalidade" (CAMPOS, 1992, p. 12).

Nos dizeres de Campos, a metalinguagem tem como grande objetivo a obra de arte, e, no nosso caso, a arte literária. O trabalho literário realiza-se na palavra que é,

\footnotetext{
${ }^{2}$ Segolin explica: cada heterônimo é um texto-personagem. Texto, porque cada um dos poetas fictícios criados por Pessoa outra coisa não é senão o conjunto de poemas ou textos poéticos que incompletamente o compõem. Personagem, porque cada um desses entes textuais vive através de/e no próprio fazer poético que, revivido a cada leitura, o concretiza e o corporifica. In: SEGOLIN, Fernando. Fernando Pessoa: Poesia, Transgressão e Utopia. São Paulo: Educ, 1992. p. 98.
} 
segundo Saussure, signo, aquilo que nomina algo existente, um outro signo. Assim, conclui-se que a palavra é o signo de um signo já existente, ou seja, uma representação.

Se a palavra representa, quando falamos de metalinguagem (falar da linguagem literária), estamos, na verdade, ponderando sobre uma representação que representa e/ou fala sobre a linguagem. Caeiro, segundo Segolin, é o único entre os "poetas-textos" “que assume o problema da irreversível separação que entre a palavra e o mundo, entre o verbo e o homem se estabeleceu, determinando a impossibilidade total de conhecimento da realidade" (SEGOLIN, 1992, p. 35). Dessa forma, fica perceptível que na obra de Caeiro temos uma metalinguagem de separação.

A metalinguagem caeiriana é a que trata da separação da linguagem-signo quando comparada com a linguagem-mundo. É assim que entende, também, Rinaldo Gama, pois "Caeiro na verdade está pondo em xeque o poder da palavra enquanto veículo para uma aproximação com o real” (GAMA, 1995, p. 103) . Em síntese, a metalinguagem caeiriana se resume em "representar falsamente a realidade" (GAMA, 1995, p. 98). Esta definição fica comprovada nas aproximações (que também desaproximam) caeirianas feitas com o advérbio de modo como:

\footnotetext{
"Eu nunca guardei rebanhos, / Mas é como se os guardasse. / Minha alma é como um pastor, / Conhece o vento e o sol / E anda pela mão das Estações / A seguir e a olhar. / Toda a paz da natureza sem gente / Vem sentar-se ao meu lado. / Mas eu fico triste como um pôr-de-sol / Para a nossa imaginação, / Quando esfria no fundo da planície / E se sente a noite entrada / Como uma borboleta pela janela. // Mas a minha tristeza é sossego / Porque é natural e justa / E é o que deve estar na alma / Quando já pensa que existe / $\mathrm{E}$ as mãos colhem flores sem ela dar por isso. // Como um ruído de chocalhos / para além da curva da estrada, / Os meus pensamentos são contentes. / Só tenho pena de saber que eles são contentes, / Porque, se o não soubesse, / Em vez de serem contentes e tristes, / Seriam alegres e contentes.[...]" (Pessoa, 1999, p. 215-216 - poema I de O Guardador de Rebanhos).
}

Conforme vimos, o advérbio de modo se apresenta justamente como construtor de outra realidade. Os dois primeiros versos já comprovam o que deve ser dito. Entre o guardar rebanhos e o "como se os guardasse" está a realização concreta do texto caeiriano. Fica a dúvida: há uma aproximação entre as duas ações, já que é perceptível certo paralelismo vocabular? Sim, porém, esta é uma aproximação que se constrói através do afastamento. Algo que acontece com a linguagem quando aproximada/ comparada com o mundo. 
No que diz respeito à obra do heterônimo-texto Ricardo Reis, o pressentimento do Fado é obedecido por todos, como diz Jacinto do Prado Coelho. Este diz ainda que a "vida é uma sucessão de mortes" (COELHO, s/ d, p. 34). Seguindo os tristes gregos, Reis segue uma filosofia de "felicidade relativa" (COELHO, s/d, p. 35), que, na verdade, não chega a ser felicidade em nenhum momento. Assim, como se questiona a metalinguagem em Reis?

A poesia desse heterônimo é uma constante fuga da comparação que Caeiro faz da poesia com o mundo, ou seja, "o texto-Reis crê na utópica afirmação do homem como sujeito, mediante uma linguagem que fielmente o representa, ao mesmo tempo que mimetiza a ordem natural de que o ser humano é parte integrante." (SEGOLIN, 1992, p.62). É somente a palavra-signo (arte) que consegue a eternidade de estar a fazer com que ele, homem, seja vivo. Em suma, a metalinguagem de Reis é aquela em que o sustenta como ser vivo não no mundo real, mas no signo, na palavra-texto que ele também é:

\footnotetext{
"Seguro assento na coluna firme / Dos versos em que fico, / Nem temo o influxo inúmero do futuro / Dos tempos e do olvido; / Que a mente, quando, fixa, em si contempla / Os reflexos do mundo, / Deles se plasma torna, e à arte o mundo / Cria, que não a mente. / Assim na placa o externo instante grava / Seu ser, durando nela." (PESSOA, 1999, p. 195 - Primeira Ode do livro primeiro de Odes de Ricardo Reis)
}

A prova derradeira de que Reis é, ao contrário de Caeiro, um homem que não quer provar nada no real está nos dois primeiros versos do poema; ao contrário de seu mestre, Reis foge da realidade e se ancora na alteridade das palavras, ou como diz: "Seguro assento na coluna firme dos versos em que fico". Assim, temos um ser-mímese que se acovarda diante do mundo empírico. E a conclusão do poema mostra que muito além de sua covardia, há uma espécie de consciência de que se não estiver preso ás palavras, fica então na mente.

Álvaro de Campos, o outro texto-autor de Pessoa, possui, segundo Jacinto do Prado Coelho, três fases: a do Opiário [...]; a do futurismo whitmaniano[..]; enfim, uma terceira fase a que chamarei pessoal por estar liberta de influências nítidas[...]" (Coelho, s/d, p. 60). Sua primeira fase decadente é muito similar aos símbolos nostálgicos de Sá-Carneiro. A segunda fase é viva, o poema tem uma sede de fazer poesia com força, que acaba desprezando a 
razão. Segundo o próprio Pessoa, a terceira fase é a do "poeta do abatimento, da atonia, da aridez interior, de descontentamento de si e dos outros (PESSOA, 1999, p. 215-216).

Longe de discutir a metalinguagem nas fases de Campos ou não, o trabalho pretende observar a manifestação em apenas um texto, como foi feito até aqui. O signo, para Campos, tem uma relação com o objeto de que fala. Os dois sentem um ao outro, numa prática verbo-sensacionista. É aí que surge o envolvimento na multiplicação discursiva do eu, na esperança de, sendo e sentindo ficticiamente tudo, lograr descobrir, nas malhas do texto, o sujeito-síntese, o sujeito impessoal e total que os discursos - normalmente centrados num eu uno e indiviso - são incapazes de nos dar (SEGOLIN, 1992, p. 73).

Com todo o problema do sujeito-textual multifacetado, temos outro estorvo surgindo que é o choque dessas múltiplas faces uma com a outra. É com esta multifacetação do sujeito-texto que ao procurar multifacetar textualmente o sujeito do discurso e fazer com que o signo verbal assuma concretamente essa pluralidade, Campos logra aproximar-se, pelo caminho inverso - o da afirmação do signo e da linguagem -, da realização do ideal visado por Caeiro, qual seja o da anulação da distância que separa o signo do seu objeto. Com efeito, a sensação existe agora no signo, que reproduz na materialidade palpável de sua forma de expressão, a multiplicidade paroxística do real. (SEGOLIN, 1992, p. 78)

A multiplicidade do texto-Campos não o faz perder a coerência textual, mas demonstra claramente que seus versos percorrem um caminho, através da linguagem, na busca desesperada de sentir tudo. Sentir inclusive com o trabalho feito com a linguagem, sentir na e com a poesia, e ao mesmo tempo em todas as outras coisas:

"Nada me prende a nada. /Quero cinqüenta coisas ao mesmo tempo. / Anseio com uma angústia de fome de carne /O que não sei que seja - / Definidamente pelo indefinido... /Durmo irrequieto, e vivo num sonhar irrequieto /De quem dorme irrequieto, metade a sonhar. /Fecharam-me todas as portas abstratas e necessárias. /Correram cortinas de todas as hipóteses que eu poderia ver da rua. / Não há na travessa achada o número da porta que me deram. /Acordei para a mesma vida para que tinha adormecido. /Até os meus exércitos sonhados / sofreram derrota. /Até os meus sonhos se sentiram falsos ao serem sonhados. / Até a vida só desejada me farta - até essa vida... / Compreendo a intervalos desconexos; / Escrevo por lapsos de cansaço; E um tédio que é até do tédio arroja-me à praia. /Não sei que destino ou futuro compete à minha angústia sem leme; /Não sei que ilhas do sul impossível aguardam-me naufrago;/ ou que palmares de literatura me darão ao menos um verso. / Não, não sei isto, nem outra coisa, nem coisa nenhuma... /E, no fundo do meu espírito, onde sonho o que sonhei, /Nos campos últimos da alma, onde memoro sem causa /(E o passado é uma névoa natural de lágrimas falsas), /Nas estradas e 
atalhos das florestas longínquas /Onde supus o meu ser, /Fogem desmantelados, últimos restos / Da ilusão final, /Os meus exércitos sonhados, derrotados sem ter sido, /As minhas cortes por existir, esfaceladas em Deus. /Outra vez te revejo, /Cidade da minha infância pavorosamente perdida... /Cidade triste e alegre, outra vez sonho aqui... / Eu? Mas sou eu o mesmo que aqui vivi, e aqui voltei, /E aqui tornei a voltar, e a voltar. /E aqui de novo tornei a voltar? / Ou somos todos os Eu que estive aqui ou estiveram, / Uma série de contas-entes. ligados por um fio memória, /Uma série de sonhos de mim de alguém de fora de mim? /Outra vez te revejo, /Com o coração mais longínquo, a alma menos minha. / Outra vez te revejo - Lisboa e Tejo e tudo - / Transeunte inútil de ti e de mim, / Estrangeiro aqui como em toda a parte, / Casual na vida como na alma, / Fantasma a errar em salas de recordações, / Ao ruído dos ratos e das tábuas que rangem / No castelo maldito de ter que viver... / Outra vez te revejo, / Sombra que passa através das sombras, e brilha / Um momento a uma luz fúnebre desconhecida, / E entra na noite como um rastro de barco se perde / $\mathrm{Na}$ água que deixa de se ouvir... / Outra vez te revejo, / Mas, ai, a mim não me revejo! / Partiu-se o espelho mágico em que me revia idêntico, / E em cada fragmento fatídico vejo só um bocado de mim - / Um bocado de ti e de mim." (PESSOA, 1999, p. 167 - Lisbon Revisited)

O poema-Campos mostra que a sua condição primordial para viver é sentir. Sua sensação se mostra absurda quando o texto diz "fecharam-me todas as portas abstratas e necessárias", mas na verdade o que ocorre é uma profunda metalinguagem da consciência inconsciente. A consciência aparece na palavra "necessidade", e a inconsciência vem nas "portas abstratas". Com efeito, a mescla entre ser e sentir que percorre o texto perdura até o final é algo engenhado - é uma clara reflexão sobre a linguagem.

Sua dúvida não é quanto à realidade, ao mundo real. Sobretudo quando verificamos um jogo arrojado de antíteses, paradoxos e oxímoros que se complementam tão confusa e harmonicamente. Sua dúvida é irremediavelmente ligada à questão do sentir. Dentro do universo pessoano, não podemos ter certeza de algo, mas algo que fica incutido em todos os textos-Campos é a percepção do sentir, mas não saber como prová-lo - inclusive quando nos referimos à linguagem, mas ele, o texto-autor, sente. Se sentir é ser, ser é sentir e o ciclo se repete infinitamente dentro do texto. Então, o heterônimo-linguagem existe na realidade empírica ao fazer-se texto.

Quanto ao ortônimo Fernando Pessoa, Segolin diz: Pessoa insiste em fazer-se texto, buscando-se não como homem, mas como o amálgama de linguagens que recobrem e ocultam sua verdade. Consciente de que, na realidade, é também símbolo, Pessoa debruça-se, ainda desta 
vez, sobre as linguagens que tecem malhas de uma pseudo-identidade e empenha-se em fazer soar os diferentes discursos que nela ecoam. (SEGOLIN, 1992, p. 96)

Seabra diz que o agigantamento de Pessoa está em ser "poeta da língua, poeta da língua portuguesa, Pessoa foi-o antes de mais por ser um poeta em poetas, um poeta da poesia” (SEABRA, 1988, p. 100) (grifo nosso). Por isso, quando Pessoa diz:

\footnotetext{
"A grande Esfinge do Egipto sonha por este papel dentro.../ Escrevo e ela aparece-me da minha mão transparente/ E o canto do papel erguem-se as pirâmides.../ Escrevo - perturbo-me de ver o bico da minha pena / Ser o perfil do rei Queóps.../ De repente paro.../ Escureceu tudo... Caio por um abismo feito de tempo.../ Estou soterrado sob as pirâmides a escrever versos à luz clara deste candeeiro / E todo o Egipto me esmaga de alto através dos traços que faço com a pena.../ Ouço a Esfinge rir por dentro/ O som na minha pena a correr no papel.../ Atravessa o eu não poder vê-la uma mão enorme,/ Varre tudo para o canto do tecto que fica por detrás de mim,/ E sobre o papel onde escrevo, entre ele e a pena que escreve/ Jaz o cadáver do rei Keops, olhando-me com olhos muito abertos,/ E entre os nossos olhares que se cruzam corre o Nilo/ E uma alegria de barcos embandeirados erra/ Numa diagonal difusa/ Entre mim e o que penso...// Funerais do rei Queóps em ouro velho e Mim!..." (PESSOA, 1999, p.21 - poema III de Chuva Oblíqua)
}

O poeta da língua identificado por Seabra é, também, um poeta do Eu. Porém, este Eu é muito peculiar. Ele vê uma além-realidade no mundo real e no texto. Sua metalinguagem discute apenas a questão da linguagem? Não. Pessoa discute em seus textos-ortônimos a questão da literatura e do ser (ou além-linguagem e além-ser). Como em todos seus textos, ortônimos ou não, a metalinguagem não fica somente na questão da linguagem artística em si, mas se relaciona com outros aspectos bem definidos: Pessoa faz-se um amálgama de linguagens.

\section{Considerações Finais}

"Eu não sou eu,/ nem sou o outro/ sou qualquer coisa de intermédio/ pilar da ponte de tédio/ que vai de mim para o outro." Mário de Sá-Carneiro

Como todos os artistas do início do Modernismo, Fernando Pessoa é um homem em transição. É neste momento que surge a maior de todas as revoluções. Os artistas do Modernismo começaram a questionar a própria arte de forma que ela entrasse em 
choque - construtivo ou não. Além de Pessoa, dentre outros, destacou-se no Modernismo português Mário de Sá-Carneiro. Os dois sempre trabalharam pela arte até o suicídio do segundo. Pessoa continuou seu labor artístico, mas a sua morte era em cada palavra escrita, aos poucos - uma agonia.

Em relação à arte, temos a metalinguagem como grande alavanca moderna, pois é ela que faz com que a arte se questione a si mesma. Vejamos o poema "Sete", de SáCarneiro, muito semelhante ao ideal pessoano. Coloquemos o "eu" do poema como a linguagem. O problema da linguagem é não ter uma identidade. A linguagem não é ela mesma, nem outra coisa. É apenas uma sustentação intermediária que percorre ela mesma e o outro.

Porém, quando o poema é visto pelo eu como Ser, temos um homem perdido, sem saber o que fazer, mas que possui um único lugar - o próprio poema. Sem saber como resolver as questões modernas expostas inicialmente, Pessoa também compartilha desse sentimento problemático que é ser moderno, mas em Pessoa é diferente: o que é a heteronímia, senão a insatisfação por não conseguir resolver o eterno problema do ser, e, no modernismo, do ser-poesia?

Pessoa resolveu o problema da metalinguagem. Ele inventou uma metametalinguagem. Ele foi além da metalinguagem, mesmo escrevendo sobre a escrita, ele conseguiu abordar também outros temas importantes para a sua constituição enquanto poeta e enquanto ser-homem:

\footnotetext{
"Durei horas incógnitas, momentos sucessivos sem relação, no passeio em que fui, de noite, à beira sozinha do mar.Todos os pensamentos, que têm feito viver homens, todas as emoções, que os homens têm deixado de viver, passaram por minha mente, como um resumo escuro da história, nessa minha meditação andada à beira-mar.

[...]

Quanto morro se sinto por tudo! Quanto sinto se assim vagueio, incorpóreo e humano, com o coração parado como uma praia, e todo o mar de tudo, na noite em que vivemos, batendo alto, chasco, e esfriase, no meu eterno passeio nocturno à beira-mar." (PESSOA, 2001, p. 125 - trecho do Livro do Desassossego)
}

Quanto à metalinguagem tradicional, ela foi transgredida por um escritor que sentia "todas as emoções que tem deixado de viver" num passeio à beira-mar. Um homem, Fernando Pessoa, que é um dos símbolos do questionamento faz com que as interrogações sobre a arte em si e sobre sua própria obra se perpetuem: Pessoa 
transformou o viver em metalinguagem para nos perguntarmos incessantemente se somos reais ou textuais.

Além do fenômeno heteronímico, temos o homem transformado em texto autoquestionativo, nos poemas: Caeiro compara e separa o mundo do texto, mas ele não vê a possibilidade de serem unívocos. A metalinguagem de Reis é o medo de sair do mundo das palavras para o real. Assim, ele continua no seu outro universo. Álvaro de Campos é o poeta-texto no significado original das palavras. Ele se sente um texto e todas as outras coisas também, mas não sabe como provar o seu sentir, apesar de ser. O Pessoa ortônimo é a realização mais complexa para a metalinguagem. Ele é um amálgama de linguagens, assim ele se questiona sobre o fazer-se todo o tempo.

Toda a obra pessoana é uma metalinguagem, mas uma metalinguagem que está muito além de ser apenas metalinguagem, como disse Haroldo de Campos: "crítica é metalinguagem. Metalinguagem ou linguagem sobre a linguagem.” A obra de Pessoa é uma metalinguagem, como dito acima, mas não é somente a sua obra, ou não é apenas crítica. Ele transforma sua poesia em vida, por isso ele é uma metalinguagem da poesia e de si mesmo. Assim, temos uma meta(persona)linguagem, afinal o falar sobre si criando personalidades que o indivíduo apresenta aos outros como real acaba na persona arquetípica definida por Jung. Pessoa e sua obra então são meta(persona)linguagem.

\section{Referências bibliográficas}

CAMPOS, Haroldo de. Metalinguagem e outras metas. $4^{\mathrm{a}}$ ed., São Paulo: Perspectiva, 1992.

COELHO, Jacinto do Prado. Diversidade e Unidade em Fernando Pessoa. $4^{\mathrm{a}}$ ed., Lisboa: Editorial Verbo, sem data.

GAMA, Rinaldo. O Guardador de signos. São Paulo: Perspectiva, 1995.

ORDOÑEZ, Andrés. Fernando Pessoa, um místico sem fé. Tradução de Sônia Regina Cardoso.Rio de Janeiro: Nova Fronteira, 1994.

PERRONE-MOISÉS, Leyla. Fernando Pessoa, aquém do eu, além do outro. $3^{\mathrm{a}}$ ed. Revista e ampliada. São Paulo: Martins Fontes, 2001. 
PESSOA, Fernando. Antologia de Estética, Teoria e Crítica Literária. Coordenação de Walmir Ayala.Rio de Janeiro: Ediouro, 1988. . Ficções do Interlúdio. Org. Fernando Cabral Martins. $1^{\mathrm{a}}$ reimpressão. São Paulo: Cia. Das Letras, 1999. . Livro do Desassossego. Org. Richard Zenith. São Paulo: Cia. Das Letras, 2001.

.Mensagem. Org. Fernando Cabral Martins. $2^{\mathrm{a}}$ reimpressão. São Paulo: Cia. Das Letras: 2000. . Textos de Crítica e de Intervenção. Lisboa: Edições Ática: 1993.

SEABRA, José Augusto. O heterotexto pessoano. São Paulo: Perspectiva: Editora da Universidade de São Paulo, 1988.

SEGOLIN, Fernando. Fernando Pessoa: Poesia, Transgressão e Utopia. São Paulo: Educ, 1992.

SERRÃO, Joel. Fernando Pessoa, Cidadão do Imaginário. Lisboa: Livros Horizonte, 1981. 